\title{
Os estereótipos dos brasileiros no guia de etiqueta da Olimpiada de Londres: uma análise da repercussão midiática*
}

\author{
The stereotypes of Brazilians in the etiquette guide for the \\ London Olympics: an analysis of the repercussion in the media \\ Los esterotipos de los brasileños en la guía de etiqueta de la
Olimpíada de Londres: un análisis de la repercusión mediática
}

Mariana Nascimento Bispo

- Mestranda do Programa de Pós-Graduação em Comunicação Social da Universidade do Estado do Rio de Janeiro (Uerj)

- Especialista em História Contemporânea pela Universidade Federal Fluminense (UFF)

- Graduada em Comunicação Social - Jornalismo pela Uerj

- marianabispo@rocketmail.com

Hugo Rodolfo Lovisolo

- Pós-doutorado em Ciências dos Esportes pela Universidade do Porto (Portugal)

- Doutor em Antropologia Social pela Universidade Federal do Rio de Janeiro (UFRJ)

- Mestre em Antropologia Social pela UFRJ

- Graduado em Sociologia pela Universidad de Buenos Aires

- Professor adjunto da Faculdade de Comunicação Social da Universidade do Estado do Rio de Janeiro (Uerj)

- Professor do Mestrado em Desenvolvimento Social do Centro Universitário Augusto Motta (Unisuam)

- Autor, dentre outras obras, de: Atividade física, educação e saúde; e Estética, esporte e educação física

- Organizador de uma série de coletâneas, entre as quais Futebol, jornalismo e ciências sociais: interaçóes; Esporte de rendimento e esporte na escola; Motus corporis

- lovisolo@globo.com

* Versão modificada e ampliada do artigo "Sensuais e pouco pontuais: a representação dos brasileiros no guia de etiquetas das Olimpíadas de 2012 e sua repercussão nos jornais brasileiros", apresentado pelos autores no IX Congresso Lusocom, em agosto de 2011, e publicado do e-book desse evento. 
O presente artigo analisa a repercussão dada por parte da imprensa nacional (jornais O Globo e Folha de S.Paulo, em suas versões on-line, e ainda o portal Uol, em sua secção de esportes), aos estereótipos dos brasileiros divulgados no guia de etiquetas da Olimpíada de Londres de 2012. Trata-se de publicação lançada pelo VisitBritain com o intuito de aprimorar a receptividade que os profissionais de turismo e os próprios londrinos darão aos visitantes que irão à capital britânica para participar do evento. Além disso, se faz uma análise comparativa dos estereótipos presentes no guia com algumas das interpretações do povo brasileiro elaboradas por estudiosos nacionais.

PALAVRAS-CHAVE: REPRESENTAÇÃO SOCIAL • IDENTIDADE • OLIMPÍADA • ESTEREÓTIPOS

Abstract

This article aims to discuss the stereotypes of Brazilians in the etiquette guide launched by VisitBritain with the purpose of improving the receptivity on the part of the tourism professionals and of Londoners for the tourists that will attend the event. The authors analyze the impact that the primer and its stereotypical representations had in three Brazilian media vehicles.

KEYWORDS: SOCIAL REPRESENTATION • IDENTITY • OLYMPIAD • STEREOTYPES

Resumen

Este artículo discute los estereotipos de los brasileños en la guía de etiqueta para los Juegos Olímpicos de Londres en 2012, una publicación lanzada por VisitBritain con el fin de mejorar la respuesta a los turistas que irán a este evento, por parte de los profesionales del turismo y de los londinenses. Se hace un análisis del impacto que dicha cartilla y sus representaciones estereotipadas tuvieron en vehículos selecionados de la media brasileña. 
0 s jogos olímpicos são um megaevento nos quais diversas nacionalidades se encontram e convivem em uma determinada cidade por um período de, pelo menos, duas semanas. Bourdieu (1997, p. 123) ressalta que há em torno desses jogos duas dimensões: uma real, por nós percebida, que é composta pelos confrontos entre atletas e pelas premiações e rituais do evento; e uma segunda, que ele afirma ser o lado midiático, ou seja, o conjunto das representações linguísticas e imagéticas do espetáculo, que é filmado e divulgado das mais diversas maneiras.

As duas dimensões salientadas por Bourdieu não parecem ser de fácil distinção para o receptor das transmissões e podem dar lugar ao entendimento de uma olimpíada real (ou essencial) e outra midiática. A maioria de nós assiste àquilo que é mediado, sobretudo, pela transmissão ao vivo da televisão, o que implica tanto os pontos de vista das câmeras, quanto os comentários de jornalistas, atletas e especialistas sobre os momentos do evento e, também, sobre antecedentes históricos, significados da prova e até da trajetória e vida dos atletas. A distinção de Bourdieu parece implicar um sociólogo platônico capaz de distinguir, no caso na tela da televisão, entre o real e as imagens projetadas. A distinção parece, como o mito das cavernas, estar servindo ao crítico e à crítica, que sabem olhar de modo válido desde uma posição privilegiada.

O guia de etiquetas, que é criado por ocasião desse evento, para apoiar a recepção dos visitantes e que divulga representações de diversas nacionalidades, pode ser entendido como mais um elemento dessa dimensão representacional, ressaltada pelo autor. O guia participa da construção do espetáculo com o objetivo de criar cordialidade e evitar conflitos. Participa, então, dos objetivos de civilidade e convívio postos para a olimpíada desde as formulações do Barão de Coubertain. Formam parte, portanto, de uma tradição, no caso, claramente inventada ou planejada, nos termos de Hobsbawn (1984).

A visibilidade dada à olimpíada, que em sua última edição, realizada em Pequim em 2008, só na cerimônia de abertura recebeu audiência de 1 bilhão de pessoas em todo o mundo ${ }^{1}$ - cerca de $15 \%$ da população mundial - deixa claro que a competição atrai atenção de espectadores de todo o planeta. Sendo assim, um guia feito especificamente para esse evento, que recebe participantes e visitantes do mundo inteiro, tem uma visibilidade intercontinental e pode espalhar as representações nele contidas por diversos países, reforçando as características descritas sobre as nacionalidades ali presentes.

Vale ressaltar que tal guia cria representações de várias nacionalidades. O presente trabalho põe o foco na parte do guia destinada aos brasileiros e no que "o outro", o estrangeiro - representado neste caso pela instituição oficial de

1 Informações da agência Reuters Brasil. Disponível em: <http://br.reuters.com/article/sportsNews/idBRN1131961520080811> 
turismo da Grã-Bretanha, a VisitBritain ${ }^{2}$ - diz sobre nós. Além de observar a recepção que o guia teve em publicações brasileiras, a partir do que fora publicado sobre o fato nos jornais O Globo e Folha de S.Paulo, em suas versões on-line, e ainda no portal Uol, em sua seção de esportes.

Norteiam nossa pesquisa os conceitos de representação, identidade e estereótipo. Realiza-se também uma comparação do estereótipo dos brasileiros divulgado pelo guia com interpretações de estudiosos nacionais sobre o Brasil e sobre seu povo, que dizem respeito ao nosso "jeito", em uma espécie de "autoanálise" dessas características que foram atribuídas a nós pelo "outro". Esse comparativo foi pensado a partir da informação dada pela VisitBritain de que as representações do guia foram criadas com ajuda de funcionários estrangeiros, que descreveram suas próprias nacionalidades.

A metodologia é a da análise de conteúdo de matérias publicadas sobre o guia. Mesmo reconhecendo as dificuldades do método, e as diferenças entre as propostas, partiremos das constatações de Fonseca Júnior (2010, p. 283), o qual ressalta que a questão da inferência vem ganhando destaque na pesquisa de conteúdo, "seja ela baseada ou não em indicadores quantitativos". Nossa análise é de cunho qualitativo e os "marcos de referência" que adotamos, nos termos de Krippendorff (apud Fonseca Júnior, 2010, p. 287), são, no caso dos dados, matérias publicadas nos referidos veículos em 11 de agosto de 2010, data do lançamento do guia, e em 12 de agosto. Portanto, outro marco referencial, o "contexto dos dados", é o dia de lançamento da publicação do VisitBritain, em um período no qual o próprio Brasil já vivia a expectativa de sediar os Jogos Olímpicos de 2016, com o consequente aumento do interesse por parte da imprensa nacional. Outro marco relevante para análise de conteúdo é a questão dos objetivos, dentre os quais o principal foi o de analisar a repercussão que os jornais brasileiros deram ao conteúdo do guia, sobretudo no que diz respeito ao estereótipo construído dos brasileiros. Porém, a partir da análise desse corpus ${ }^{3}$ e das informações por ele fornecidas, outros objetivos foram sendo traçados. Assim, buscamos comparar o que fora dito pelo guia sobre os

2 É a agência nacional de turismo da Grã-Bretanha. Trata-se uma organização de natureza privada responsável pelo seu próprio conteúdo. 0 governo do Reino Unido, apesar de apoiar financeiramente a organização, não tem assento na mesa diretora e não influi na eleição das informações que devam ou não ser divulgadas (Merguizo, 2010).

3 Acerca da construção do corpus nesse tipo de método, Júnior (2010) cita autores como Bardin (1988) e Barros e Targino (2000) para informar que há algumas regras para a sua construção, entre as quais a da exaustividade, ou seja, a de que todos os documentos relativos ao assunto pesquisado devem ser considerados. Outra seria a da representatividade, ou seja, já que no universo das ciências sociais os elementos contidos são muito amplos, torna-se impossível analisá-los em sua totalidade, fazendo-se necessário, portanto, trabalhar com uma amostra. E tal amostra deve ser definida, dentre outros critérios, pelo tipo de análise a ser feita, qualitativa ou quantitativa. Como no caso do presente trabalho o objetivo é uma análise mais aprofundada e menos estatística, a quantidade de periódicos consultados ficou reduzida a três. E, de acordo com as regras da homogeneidade e da pertinência (Barros e Targino, apud Fonseca Júnior, 2010, p. 292-293) as fontes são todas da mesma natureza - matérias de jornais, publicadas em versão on-line, no dia do lançamento do guia, bem como no dia seguinte. 
brasileiros, e como os jornais do país o repercutiram, com algumas das mais conhecidas e tradicionais interpretações do Brasil e do "ser brasileiro", feitas por autores nacionais. Partimos da hipótese de que os estereótipos atribuídos pelo referido guia talvez tenham sido construídos por estudiosos brasileiros.

Em nosso entender, o eixo central é a afirmação de que "a tarefa de toda análise de conteúdo consiste em relacionar os dados obtidos com alguns aspectos de seu contexto" (Fonseca Júnior, 2010, p. 288). Assim, além das comparações com interpretações de autores brasileiros, fazemos inferências sobre os estereótipos presentes nas dicas do guia da olimpíada e sobre a questão de se essas construções seriam ou não pertinentes para a natureza da publicação.

\section{GUIA DA OLIMPÍADA: UM DIVULGADOR INTERNACIONAL DE REPRESENTAÇÕES, IDENTIDADES E ESTEREÓTIPOS}

Para seguir com a análise do guia de etiquetas e da repercussão das dicas referentes aos brasileiros na imprensa brasileira, faz-se necessário apontar algumas características de dois conceitos que se complementam: o de representação e o de identidade.

O termo representação pode ser descrito, de forma simplificada, como "algo que alguém nos conta sobre algum aspecto da vida social” (Becker, 2009, p. 18). Tal definição abarca diversos setores da vida social, entre os quais a representação dos indivíduos e dos grupos. Hall (apud Torres, 2006, p. 6), por sua vez, no campo dos estudos midiáticos, discorre sobre a função da representação, dizendo que ela "atua simbolicamente para classificar o mundo e nossas relações no seu interior”.

No que diz respeito aos grupos e povos, emerge também a questão da identidade. Sobre esta Castells (1998) diz ser ela a fonte de "significado e experiência de um povo, com base em atributos culturais relacionados que prevalecem sobre outras fontes”. A generosa definição de Castells poderia ser aplicada também ao conceito de tradição, que habitualmente indica como somos no fluxo de uma narrativa histórica. Assim, a identidade seria uma dimensão forte da tradição? Ela não deve ser confundida com papéis, enfatiza Castells, pois estes determinam funções, enquanto a identidade organiza significados. Já para Ortiz (1994) a identidade define-se em relação ao exterior: ela é uma diferença. $\mathrm{O}$ autor afirma ainda que insistimos em buscar uma identidade que se contraponha ao estrangeiro. Sobre esse mesmo tema Schneider (2004) cita Benedict Anderson, ao afirmar que "comunidades nacionais são fortes referências para a formação da identidade", e menciona ainda os antropólogos George Devereux (1978) e John Armstrong (1982) para explicar que as identidades étnicas funcionam, basicamente, como um "dispositivo de rotulagem". "Assim, a formação do grupo e da identidade são ambos processos que não estão necessariamente vinculados a 'comportamentos culturais' específicos”' (Schneider, 
2004). O autor levanta também a hipótese de que, mais do que procurar o locus social e cultural da identidade e o sentimento de comunhão por ela gerado, é necessário também associá-la à "mediação ou transmissão de narrativas-mestras" da nação a seus membros. O "discurso" teria, segundo Schneider, um papel fundamental na transmissão e construção destas narrativas e modos e expressão que unem uma comunidade nacional'5 . De modo geral, cultura e identidade nacional aparecem como caras da mesma moeda ou como dois modos de tratar a diferença.

Silva (2007) reforça essa ideia do papel do discurso no processo de construção e difusão da identidade ao afirmar que as categorias identidade e diferença são interdependentes ${ }^{6}$ e resultados de "atos de criação linguística". Schneider (2004), no entanto, ressalta que em uma perspectiva etnográfica, as identidades nacionais serão sempre uma "hipersimplificação e/ou generalização". Depreende-se disso que nem todos os integrantes de determinada nacionalidade terão os mesmos hábitos, comportamentos e características atribuídas ao povo nas representações da identidade.

Portanto, quando se fala que os brasileiros "são assim" e os argentinos são "de outro jeito", faz-se isso de maneira generalista e simplificadora. Resta saber se poderia ser feito de uma forma não redutora. Nós diríamos que a definição do conjunto dos elementos é redutora do conjunto das diferenças entre os elementos. Assim, se definirmos, como o guia o faz, as brasileiras como sensuais, é porque ignoramos as diferenças entre elas. De fato, nem todo brasileiro é bom de samba no pé.

0 guia e suas dicas: uma reflexão sobre a questão das

identidades nacionais e sobre a função dos estereótipos

O guia da olimpíada que formula conselhos aos londrinos acerca dos turistas que eles irão receber em sua cidade, em 2012, foi veiculado pelos principais jornais impressos e on-line do mundo e do Brasil, bem como no site oficial da VisitBritain. Ele codifica as formas como devem ser tratados os estrangeiros

4 Schneider (2004) define discurso como um sistema formativo inter ou supraindividual, voltado para as narrativas e para a construção de significado, implicando sua "imersão" [embeddness] em um contexto mais abrangente.

5 Disponível em <http://www.scielo.br/scielo.php?script=sci_arttext\&pid=S0104-93132004000100004\&lang=pt $>$.

6 Para esse autor, identidade pode ser definida "como aquilo que se é", e neste sentido seria algo que tem como referência a si mesmo, autorreferente. Já a diferença pode ser definida como aquilo que "o outro é". E, apesar de autorreferentes, esses conceitos são interligados. Como exemplo dessa afirmação, ele cita: "'Sou brasileiro' - ponto. Entretanto, eu só preciso fazer essa afirmação porque existem outros seres humanos que não são brasileiros" (Silva, 2007)

7 Para o autor, pela própria magnitude do grupo em questão, este se torna um dilema empírico insolúvel (Schneider, 2004) 
que forem visitar Londres durante os jogos, em função de suas identidades nacionais. Entre as dicas de uma boa receptividade aos turistas estão as seguintes:

Brasileiros: não pergunte sobre idade, salário, estado civil e não fale de seus rivais, os argentinos; japoneses: sempre estão sorrindo, mas não estão necessariamente felizes; franceses: podem ser rudes e exigentes; Canadenses: nunca confunda com americanos; argentinos: têm humor peculiar e deve-se tomar cuidado a servir vinho a eles; poloneses: bebem excessivamente; belgas: estalar os dedos para eles pode ser uma ofensa; australianos e neozelandeses: usam linguagem vulgar, mesmo não querendo ofender; mexicanos: não fale em imigração, pobreza e terremotos com eles (Merguizo, 2010).

No Brasil, veículos como "Uol esportes” e O Globo divulgaram uma lista ampliada das recomendações dadas pelo VisitBritain aos londrinos para recepcionar o povo brasileiro. Dentre elas, as de que os brasileiros não costumam respeitar horários e recorrem facilmente a beijos e abraços (que, segundo o texto, "não têm conotação sexual, mas são demonstrações de amizade") (Merguizo, 2010). Outra observação é que as mulheres brasileiras se vestem quase sempre de maneira sensual.

O Globo e a Folha.com tentaram investigar em suas matérias quem foram os responsáveis pela autoria de tais dicas. Descobriram que os conselhos foram escritos por funcionários estrangeiros da agência britânica sobre seus países de origem. Ou seja, há uma forte influência da autorrepresentação nacional na construção do guia. Assim, a maneira como os brasileiros são vistos na publicação teria sido influenciada pelas respostas dos brasileiros consultados.

Teria sido então um brasileiro que descreveu seus próprios conterrâneos como pessoas "pouco pontuais" e que têm uma "noção de espaço pessoal menor do que outras culturas"? (Uol, 2010). Esta questão da "noção de espaço pessoal menor" diz respeito ao hábito dos brasileiros de beijar e abraçar os amigos e colegas e de ter mais contatos de toques com as pessoas em geral. Na verdade, o beijo na face entre os argentinos homens é bem mais comum do que entre os brasileiros; contudo, este fato não é citado. Teria sido porque os informantes argentinos não destacaram essa conduta habitual, entre os homens amigos, por excesso do hábito? Portanto, é interessante ressaltar que estamos trabalhando com seleções e recortes na construção da identidade que são os que interessaram na elaboração das identidades no guia.

\section{Identidades: é possível estabelecer subcategorias para o conceito?}

A identidade é relacional, pode operar por contraposição, produz significados e experiências e, assim como as representações, classifica e orienta por meio do dispositivo de rotulagem. Identidade e representação operam mediante narrativas, processos simbólicos e linguísticos. Em outras palavras, as repre- 
sentações sobre a identidade nacional ocupam um lugar de destaque na análise das representações, que encontrou um campo privilegiado de aplicação no campo das "identidades nacionais".

Das características listadas sobre a representação e a identidade podemos inferir uma ampla área comum. Possivelmente, isso resulte do fato de os autores supracitados, bem como os autores do guia da Olimpíada de Londres, estarem trabalhando com representações, narrativas ou elaborações simbólicas da identidade nacional. No caso do presente trabalho, são conceitos que se interpenetram e que, portanto, se apresentam como de difícil distinção teórica. A diferenciação conceitual entre eles depende apenas do ângulo ou foco, que nas análises frequentemente se desloca de uma para o outro. Permanece a questão: não ficaria mais claro se falássemos de representação de identidades nacionais? Acreditamos que esse caminho eliminaria algumas confusões. A representação de identidades nacionais seria apenas um subconjunto, embora importante, da análise das representações. Também poderíamos falar das representações de identidades de gênero, criando um código comum para nos referirmos aos problemas que tangem essas questões.

Estudados em linhas gerais os conceitos de representação e identidade, cabe neste momento do trabalho acrescentar mais um conceito, que está diretamente relacionado à representação: o de estereótipo.

\section{Os estereótipos e sua função social}

Arruda, Gonçalves e Mululo (2008, p. 504) apontam como um dos componentes das representações sociais os estereótipos. Estes podem ser considerados como uma forma reduzida de representação ${ }^{8}$, porém as definições acerca desse termo na psicologia social estão longe de serem unívocas; ao contrário, são variáveis e mutáveis.

Maisonneuve (1973) observou algumas características principais inerentes ao conceito, entre as quais a uniformidade. O autor afirma que os estereótipos em geral se difundem de maneira uniforme em determinado grupo ou determinada população. Outras questões pertinentes são a simplicidade e a pobreza das características evocadas por eles e a pregnância, "que implica graus de adesão variável, chegando até a sua integração a sistemas de valores e de condutas dos sujeitos" (Moscovici e Jodelet, apud Arruda, Gonçalves e Mululo, 2008, p. 505). O tom afetivo e a falta de neutralidade também estão presentes nos este-

8 “0 estereótipo não apresenta a mesma complexidade da representação social, que, para elaborar o objeto, agencia um universo de opiniões, juízos, afetos e imagens, como afirmam Moscovici (1978) e Jodelet (2001). A representação se estrutura num campo que contém imagens e modelos articulados e hierarquizados, nem todos da mesma precisão de um estereótipo, embora uma representação social possa dar origem a um estereótipo. Essa, contudo, não é uma relação necessária" (Moscovici e Jodelet, apud Arruda, Gonçalves e Mululo, 2008, p. 505). 
reótipos, assim como o conteúdo cheio de "indicadores sumários" distintivos, que permitem identificar o objeto. Assim, para Moscovici e Jodelet (apud Arruda; Gonçalves; Mululo, 2008, p. 504), bem como para outros autores, "todo estereótipo se caracterizaria pela rigidez, esquematismo, tonalidade avaliativa e especificidade". Vale ressaltar, no entanto, que nem todos os autores veem os estereótipos necessariamente como negativos.

Para Arruda, Gonçalves e Mululo (2008), eles possuem funções sociais, entre as quais a de possibilitar uma economia cognitiva, já que a partir deles sistematizamos percepções e nos comunicamos mais facilmente. Além disso, funcionam como uma categorização que permite aos grupos distinguirem-se "dos outros" em oposição a si próprios. A simplicidade dos estereótipos facilita a comunicação e permite a diferenciação. Contudo, os que têm uma imagem mais negativa do termo poderiam afirmar que eles também estão na base da violência presente na relação com os outros específicos na interação social. Ou seja, aquilo que Arruda, Gonçalves e Mululo consideram como positivo, poderia ser listado, por outros autores, no lado pejorativo dos estereótipos. Em outros termos, os estereótipos construídos podem constituir uma boa base para a segregação, a descriminação e a violência. Portanto, o significado, positivo ou negativo, nos remete ao campo da pragmática ou do uso, como para muitos é o caso da energia atômica.

O estereotipo parece ser definido por traços negativos (uniformidade, simplicidade, pobreza, afetividade, falta de neutralidade, rigidez e esquematismo, entre outros). A negatividade constitutiva, cujos signos podem ser invertidos, vai acompanhada, entretanto, de uma considerável capacidade de difusão e adesão. Parece, então, que os seres humanos gostam de operar com os traços negativos dos estereótipos.

Os estereótipos parecem remeter ao modelo da bactéria, em aspectos principais, tais como: se reproduz muito bem, se adapta facilmente e todos são portadores de uma boa quantidade delas. Há uma diferença: distinguimos entre bactérias "boas" e "ruins" e reconhecemos que não existiríamos sem elas. Mais ainda, podemos sintetizar bactérias "boas" ou funcionais para a vida humana. A questão então é: existiriam estereótipos funcionalmente "bons" e sem os quais não poderíamos viver? Ou as características, dependendo da configuração social da qual formam parte, poderiam funcionar como bactérias ruins ou boas?

Focando na olimpíada: os estereótipos construídos ajudarão a coordenar as relações humanas desse grande evento? Os organizadores parecem que já deram uma resposta positiva a essa questão, baseados, talvez, na prática dos relacionamentos e na "observação" de suas regularidades empíricas. Os estereótipos, pelo que podemos inferir, pelo menos para a equipe que fez a cartilha turística da olimpíada, ajudariam a coordenar o evento, tanto que se valeram deles para montar a publicação. 
Nesse sentido, as representações presentes no guia de etiqueta do VisitBritain são estereotipadas, mas não necessariamente ressaltam características negativas ou possuem traços difamatórios em seus discursos sobre "o outro". Eles trazem uma série de estereótipos associados às características de cada nacionalidade, as quais os elaboradores do guia acreditam ser coerentes com os comportamentos daqueles povos na realidade. E, na perspectiva do referido órgão de turismo daquele país, tais estereótipos podem ajudar na boa recepção que esses povos terão dentro do Reino Unido. Tanto que a diretora-executiva da agência que criou o guia, Sandie Dawe, ressaltou em entrevista a periódicos britânicos, reproduzida pelos jornais brasileiros, que essa era a idéia ao se criar a publicação: dar uma boa receptividade aos visitantes ${ }^{9}$.

Neste ponto, cabe a reflexão de $\operatorname{Becker}(2009$, p. 31), o qual afirma que qualquer representação da realidade é necessariamente parcial "e menos do que experimentaríamos e teríamos à nossa disposição para interpretar se estivéssemos no contexto real do que ela representa". Afinal, segundo o autor, é por isso que se fazem representações: "para relatar apenas aquilo de que os usuários precisam para realizar o que quer que queiram fazer". Entretanto, não seria por termos a representação que podemos registrar aquilo que experimentaríamos e interpretaríamos se estivéssemos no contexto real na qual a usamos?

Partindo dessa função da representação e dos estereótipos, as narrativas criadas no guia para ajudar os londrinos a lidar com os estrangeiros não são negativas, nem pejorativas, nem positivas e favoráveis, mas sim discursos que pretendem servir, de forma prática, à conduta daqueles que serão anfitriões e, nesse sentido, são adequadas ao que se propõem resolver, em certa medida. Afinal, na concepção dos funcionários do órgão de turismo inglês responsáveis por redigiram a cartilha, aos profissionais de turismo de seu país e aos londrinos, só basta saber certas características dos brasileiros e de outros povos, para bem recebê-los.

Ademais, como se trata de um evento esportivo, retratar a questão do não-cumprimento dos horários é pertinente e, como é uma festa de congraçamento, a questão de como os povos se relacionam no campo pessoal também é relevante. Quanto ao quesito "rivalidade”, já que teremos diversas nacionalidades convivendo em Londres, as relações de amizade ou "implicância" entre os visitantes também são algo que pode ser útil ao anfitrião conhecer, ainda que de forma estereotipada e simplificada.

\section{As interpretações dos jornais sobre o guia}

Conforme já dito, as representações do guia de etiquetas foram criadas para uma função específica: levantar algumas características dos povos que circu-

9 “Dar aos nossos visitantes estrangeiros uma recepção acolhedora é absolutamente vital para a nossa economia. Esta foi a afirmação da ministra a respeito do conteúdo do guia" (Folha.com, 11/08/2010). 
larão em Londres, de modo que estes possam ser bem recebidos pelos londrinos. Porém, o que se disse de cada povo acerca de suas próprias características incomodou os representados, no que tocava a si próprios. Os jornais franceses, por exemplo, deram ênfase ao que se disse deles, neste caso a "rudeza" a eles atribuída. Diversos jornais brasileiros fizeram o mesmo e, na interpretação do "lançamento do guia de etiquetas e suas representações", levaram o fato para o lado pejorativo e priorizaram o que fora dito sobre os brasileiros.

Nas reportagens do jornal O Globo, em sua versão on-line, e na Folha.com, bem como no "Uol esportes", o discurso nas matérias era de que havia nas dicas certa ofensa aos brasileiros e aos outros povos. A Folha.com, em sua seção de esportes, no dia 12 de agosto de 2010, chegou a publicar, como assunto de suíte $^{10}$ da notícia do lançamento do guia, a posição da embaixada brasileira em Londres acerca das representações divulgadas. Esse órgão se absteve de qualquer crítica com relação à publicação. E a chefia de comunicação da instituição, em entrevista ao referido jornal, afirmou não ter considerado o conteúdo do guia ofensivo (Merguizo, 2010).

Neste ponto, cabe ressaltar a reflexão de Becker (2009) sobre os "fatos" e as "interpretações". Para esse autor, uma parte de qualquer relato sobre a sociedade é de como as coisas são. E a outra parte é o que se pensa sobre esses fatos, as interpretações. Poderíamos agregar que temos relatos sobre como as coisas são, relatos sobre como deveriam ser, interpretações sobre como as coisas são e interpretações sobre como as coisas deveriam ser. E, no caso desse guia, os jornais do Brasil já deram, ao publicar a noticia, uma interpretação para as dicas sobre os brasileiros, e em um tom pejorativo que indica não serem as coisas como os ingleses dizem que são e que deveriam ser representadas de outra forma.

O próprio termo estereótipo é usado nas matérias com um sentido negativo. O título da matéria de O Globo, por exemplo, diz que o guia "abusa dos estereótipos" (Globo.com, 11.08.2010). O emprego do "abusa” dá a ideia de que o autor do referido texto considera os estereótipos algo ruim.

\section{ALGUMAS AUTORREPRESENTACÕES DOS BRASILEIROS: UM COMPARATIVO COM AS OUESTÕES LEVANTADAS NO GUIA}

No que tange às principais características a nós atribuídas pela publicação da VisitBritain, ou seja, o atraso de horários, a sensualidade no vestir, a questão do toque e do carinho com o outro - que é encarado pelos britânicos como uma noção diferente do espaço do outro - alguns autores brasileiros atribuíram em seus estudos algo próximo a isso, como sendo características da "brasilidade" e dos brasileiros. Criaram interpretações do Brasil e de seu povo as quais não

10 Matéria que dá sequência ou continuidade a uma noticia. 
são tão divergentes do que fora atribuído ao brasileiro no guia de etiquetas. Estaríamos diante de sinais que indicam que a criação dos estereótipos foi local e seu reconhecimento é internacional?

Sérgio Buarque de Holanda, por exemplo, fala, em sua obra Raízes do Brasil, do tipo de brasileiro que ele denominou neoportuguês, cuja principal característica de personalidade é a cordialidade. Esse traço, segundo ele, não se restringiria às relações pessoais, mas seria "uma característica da sociedade brasileira em geral" (Holanda, apud Reis, 2002, p. 134) Esse tipo cordial trata os desconhecidos como se fossem irmãos, primos e agregados, e seu comportamento social não é objetivo, mas sim "afetivamente transbordante". Um homem que, segundo Holanda, "tem horror as distâncias, e se elas existem concretamente, ele simplesmente as abole". O pensamento do autor vai ao encontro do que fora dito sobre o brasileiro no guia. Ou seja, a descrição de um povo que gosta de beijar e abraçar e que tem uma noção do espaço pessoal do outro mais ligada à proximidade do que ao distanciamento. Porém, observa-se que o guia ressalta que, ao mesmo tempo em que gosta de proximidade, no sentido de toque, o brasileiro não gosta de falar sobre sua vida pessoal, como fica implícito na passagem "não pergunte sobre idade, salário, estado civil". Não gosta de dar intimidade aos desconhecidos, podemos inferir.

A questão da sensualidade do brasileiro fora abordada por Freyre (1992, apud Arruda, Gonçalves e Mululo, 2008, p. 508) como uma característica constantemente associada a este povo pelos estrangeiros. O próprio Freyre ressalta em sua obra a relevância do olhar "do outro", do "de fora", para se entender a própria identidade. Ele ressaltou que construiu boa parte de sua visão sobre o povo brasileiro - a qual culminou no livro Casa grande \& senzala - durante o período de três anos em que viveu em terras estrangeiras. Foi uma visão de fora, do exterior, "não familiar" que lhe teria revelado pela primeira vez a figura do brasileiro que ele traçou (Freyre, apud Reis, 2002, p. 64). Textos de Roberto Damatta poderiam ser aproximados do estereótipo construído no guia e algumas músicas de Adriana Calcanhoto, também. $\mathrm{O}$ leitor pode completar a lista.

Sobre a rivalidade entre brasileiros e argentinos, Helal e Lovisolo (2009) afirmam que foi a partir da rixa criada pela imprensa esportiva, tanto brasileira como argentina, que começaram a se acirrar os estereótipos de um país em relação ao outro. E foi a partir de 1998, ano da Copa do Mundo na França, que eles observaram na imprensa ${ }^{11}$ brasileira "sentimentos 'antiargentinos', que pareciam extrapolar o universo esportivo” (Helal; Lovisolo, 2009, p. 12) Além disso, em 2002, eles identificaram um crescimento dos estereótipos negativos extracampo sobre os argentinos nos discursos dos jornais estudados. Entre

11 Os jornais analisados pelos autores foram 0 Globo e o Jornal do Brasil no período de 1970 a 2002 e nas duas partidas que ocorreram entre Brasil e Argentina em junho de 2005 - eliminatórias da Copa de 2006 e final da Copa das Confederações (Helal; Lovisolo, 2009, p. 1). 
os termos depreciativos referentes aos vizinhos eles encontraram "empáfia", "arrogância" e "racista". "A análise mostra que a provocação é mais forte do lado brasileiro, que usa categorias negativas sobre o futebol, os jogadores e os argentinos de modo geral" (Helal; Lovisolo, 2009, p. 13). Os autores verificaram ainda, por meio da análise do discurso da imprensa esportiva, que a implicância é maior do lado brasileiro, do que o inverso, e que tal rivalidade passou a extrapolar as "quatro linhas." Nas próprias matérias sobre o guia da olimpíada, parecia haver certa "satisfação" dos jornalistas ao descreverem que os

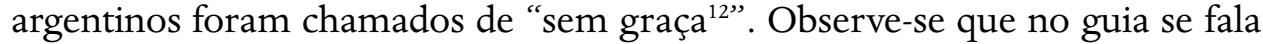
do "humor peculiar" dos argentinos, peculiar e com humoristas traduzidos internacionalmente. Ou seja, a interpretação do lado brasileiro é bem peculiar!

Diante dessas análises - ainda que pontuais e de autores específicos -, verifica-se que, em geral, algumas das características atribuídas aos brasileiros no guia de etiquetas são afirmadas pelos próprios intelectuais brasileiros como características de seu povo. Já no discurso dos jornais O Globo e Folha de S.Paulo, tais estereótipos imputados aos brasileiros não foram bem aceitos, tendo sido interpretados com um tom mais negativo do que positivo.

\section{CONSIDERAÇÕES FINAIS}

Por meio do estudo do guia da Olimpíada de Londres e das representações nele presentes sobre os mais diversos povos, bem como da repercussão desse assunto na imprensa nacional, verificam-se algumas questões. A primeira, a de que os estereótipos e as representações têm suas funções; neste caso, a função era a de serem facilitadoras de um relacionamento entre pessoas de nações diversas que serão recebidas por um mesmo povo.

Porém, pelo menos para algumas publicações brasileiras, no caso, O Globo, Folha de S.Paulo e Uol (em sua seção de esportes), o termo representação ainda é visto de forma negativa e pejorativa. Além disso, tais veículos interpretaram negativamente as representações feitas sobre os brasileiros, talvez em um movimento de acharem que qualquer representação estereotipada é ruim ou, simplesmente, por considerarem, mesmo que de forma não revelada, que os estereótipos presentes no guia se aplicam aos outros e não aos brasileiros.

Quanto à análise das dicas dadas sobre os brasileiros no guia com base em autores brasileiros, observou-se que alguns estudiosos de renome na questão da identidade nacional, responsáveis por criar algumas interpretações do Brasil e dos brasileiros, dentre eles Gilberto Freyre e Buarque de Holanda, desenvolveram teorias que, de certa forma, corroboravam o que fora descrito no guia.

E, no que tange à rivalidade entre brasileiros a argentinos, sobre a qual foi dada

12 Com o sentido de sem senso de humor. 
a dica aos londrinos de não citarem os hermanos perante os brasileiros, Helal e Lovisolo (2009) mostraram que os brasileiros "amam odiar os argentinos" e que isso foi induzido, em grande parte, de uma rivalidade surgida pelo discurso da imprensa esportiva. Entretanto, se o guia não coloca nos estereótipos dos argentinos sua rivalidade com os brasileiros, devemos deduzir que ela é mais importante para nós do que para eles? A primeira resposta seria positiva, mas merece ser mais bem trabalhada.

Por fim, fica um exercício para a Olimpíada de 2016 e - por que não? - para a Copa de 2014, competições nas quais seremos os anfitriões e iremos receber "o mundo" aqui no Brasil. Se, na ocasião, a Embratur ${ }^{13}$ ou algum órgão de turismo estadual tiver que criar um tipo de guia parecido com esse, será que também não irá se valer de estereótipos criados a partir da percepção que nós já temos das diversas nacionalidades? Será que não iremos retratar os britânicos como pontuais, frios e formais?

A principal conclusão talvez seja banal: elaboramos estereótipos dos outros e de nos mesmos. Entretanto, não gostamos quando somos estereotipados, mesmo que sobre a base das reduções elaboradas por nos mesmos.

\section{REFERÊNCIAS}

ARRUDA, Ângela; GONÇALVES, Luana P. Vital; MULULO Sara C. Cabral. Viajando com jovens universitários pelas diversas brasileirices: representações sociais e estereótipos. Psicologia em Estudo, Maringá, v. 13, n. 3, p. 503-511, jul./set. 2008.

BECKER, Howard S. Falando da sociedade: ensaios sobre as diferentes maneiras de representar o social. Rio de Janeiro. Jorge Zahar Editor, 2009.

BOURDIEU, Pierre. Os jogos olímpicos. In: Sobre a televisão. Rio de Janeiro: Jorge Zahar Editor, 1997.

CASTELLS, Manuel. 0 poder da identidade. Vol. 2. A era da informação: economia, sociedade e cultura. Rio de Janeiro: Paz e Terra, 1998.

FOLHA.COM. Londres faz guia para 2012 e diz que brasileiro não gosta de intimidades e de argentinos. São Paulo, 11.08.2010. Disponível em: <http://www1.folha.uol.com.br/esporte/781342-londres-faz-guia-para-2012-e-diz-que-brasileiro-nao-gosta-de-intimidades-e-de-argentinos.shtml>.Acesso em: 03 ago. 2011.

FONSECA JÚNIOR, Wilson Corrêa da. Análise de conteúdo. In: DUARTE, Jorge; BARROS, Antônio (Org.). Métodos e técnicas de pesquisa em comunicação. São Paulo: Editora Atlas, 2010.

GLOBO.COM. Guia britânico abusa de estereótipos ao ensinar como lidar com visitantes nas Olimpíadas de Londres-2012. Rio de Janeiro, 11.08.2010. Disponível em: < http://oglobo.globo.com/esportes/mat/2010/08/11/guia-britanico-abusa-de-estereotipos-ao-ensinar-como-lidar-com-visitantes-nas-olimpiadas-de-londres-2012-917371133.asp >. Acesso em: 18 ago. 2010.

MERGUIZO, Marcel. Embaixada diz que estereótipo de brasileiro em guia olímpico de Londres não é ofensivo. Folha.com, São Paulo, 12.08.2010. Disponível em: <http://www1.folha.uol.com.br/esporte/781767-embaixada-diz-que-estereotipo-de-brasileiro-em-guia-olimpico-de-londres-nao-e-ofensivo.shtml>. Acesso em: 30 jul. 2011.

HELAL, Ronaldo G.; LOVISOLO, Rodolfo H. Argentinos e brasileiros ou do "odiar amar" e do "amar odiar". 2009. Disponível em: http://lasa.international.pitt.edu/members/congress-papers/lasa2009/files/HelalRonaldo.pdf

13 Autarquia especial do Ministério do Turismo responsável pela execução da Política Nacional de Turismo no que diz respeito a promoção, marketing e apoio à comercialização dos destinos, serviços e produtos turísticos brasileiros no mercado internacional. Definição retirada do site oficial do órgão: < http://www. turismo.gov.br/turismo/o_ministerio/embratur/>. 
HOBSBAWN, Eric; RANGER, Terence (Org.). A invenção das tradições. Rio de Janeiro: Paz e Terra, 1984.

MAISONNEUVE, Jean. Introduction à la psychosociologie. Paris: PUF, 1973.

REIS, José Carlos. As Identidades do Brasil de Varnhagen a FHC. Rio de Janeiro: FGV, 2002.

SCHNEIDER, Jens. Discursos simbólicos e símbolos discursivos: considerações sobre a etnografia da identidade nacional. Revista Mana - Estudos de Antropologia Social, Rio de Janeiro, UFRJ, v. 10, n. 1, abr. 2004. Disponível em: <http://www.scielo. $\mathrm{br} /$ scielo.php?script=sci_arttext\&pid $=$ S0104-93132004000100004\&lang $=\mathrm{pt}>$.

SILVA, Tadeu T. da. A produção social da identidade e da diferença. 2007. Disponível em: < http://ead.ucs.br/orientador/turmaA/ Acervo/web_F/web_H/file.2007-09-10.5492799236.pdf >.

UOL. Guia para Londres-2012 diz que brasileiro só se atrasa e argentino é sem graça. Disponível em: <http://esporte.uol. com.br/ultimas-noticias/2010/08/11/para-receber-turistas-olimpicos-orgao-britanico-apela-aos-estereotipos.jhtm >. Acesso em: 03 ago. 2011.

\section{Sites acessados}

Agência Reuters: http://br.reuters.com/article/sportsNews/idBRN1131961520080811>.

Acesso em: 19 ago. 2010.

VisitBritain: <http://www.visitbritain.com/pt/BR/>.

Recebido em: 31.08.2011 / Aceito em: 21.10.2011 